\title{
In vitro activity of thienyl-2-nitropropene compounds against Trypanosoma cruzi
}

\author{
Cristina Herrera ${ }^{1}{ }^{+}$, Gabriel A Vallejos ${ }^{2}$, Randall Loaiza ${ }^{3}$, Rodrigo Zeledón ${ }^{3}$, \\ Andrea Urbina ${ }^{3}$, Silvia Sepúlveda-Boza ${ }^{4}$ \\ ${ }^{1}$ Instituto de Investigaciones Farmacéuticas, Facultad de Farmacia, Universidad de Costa Rica, San José, Costa Rica ${ }^{2}$ Instituto de Química, \\ Facultad de Ciencias, Universidad Austral de Chile, Valdivia, Chile ${ }^{3}$ Laboratorio de Zoonosis, Escuela de Medicina Veterinaria, \\ Universidad Nacional, Heredia, Costa Rica ${ }^{4}$ Laboratorio Emory Black, Escuela de Medicina, Facultad de Ciencias Médicas, \\ Universidad de Santiago de Chile, Santiago, Chile
}

The in vitro activity of four 2-nitropropene derivatives, 1-(3-benzothienyl)-2-nitropropene (N1), 1-(3-thienyl)-2nitropropene (N2), 1-(5-bromo-2-thienyl)-2-nitropropene (N3) and 1-(4-bromo-2-thienyl)-2-nitropropene (N4), were tested against cultures of the parasite Trypanosoma cruzi. Cytotoxicity studies were performed using Vero cells. The blood trypomastigotes, amastigotes and epimastigotes showed differential degrees of sensitivity towards the four tested compounds; the highest activity against the epimastigotes and blood tripomastigotes was exhibited by N1, followed by N3, N4 and finally N2. In contrast, whereas the compounds N1, N3 and N4 exerted similar magnitudes of activity against amastigotes, $N 2$ was found to be a much less potent compound. According to our results, the compound N1 had the highest level of activity $\left(I C_{50}: 0.6 \mu M\right)$ against epimastigotes.

Key words: Trypanosoma cruzi - thienyl-2-nitropropene compounds - Chagas disease - antitrypanosomal activity

Chagas disease, caused by Trypanosoma cruzi, is responsible for significant economic and public health burdens in Latin America (Dias et al. 2002, Urbina 2002, Moncayo 2003, Cerecetto \& González 2008). The drugs currently in use for the treatment of Chagas disease are nifurtimox (4[(5-nitrofurfuryl-idene)amino]-3-methylthiomorpholine-1,1-dioxide), which is derived from nitrofuran (Lampit ${ }^{\circledR}$, Bayer), and benznidazole ( $N$-benzyl-2nitroimidazole-1-acetamide) (Rochagan ${ }^{\circledR}$, Roche). Both of these drugs are trypanocidal for all forms of the parasite (Mady et al. 2008, Mecca et al. 2008) and act via the production of free radicals by a metabolic pathway. As enzymes that scavenge free radicals are either absent or have very low levels of activity in the parasite, T. cruzi is highly susceptible to the damage that is induced by these metabolites (Urbina 1999, 2002 Docampo 2001). The two drugs listed above are more effective during the acute phase of the disease. During the chronic phase, their activity is limited. Additionally, nifurtimox and benznidazole can also cause systemic toxicity and adverse effects that include anorexia, nausea, vomiting, headache, central nervous system depression, maniacal symptoms, seizures, vertigo, paraesthesias, peripheral polyneuropathies and dermatitis (Coura \& De Castro 2002, Urbina \& Docampo 2003, Kirchhoff 2005, Rodríguez 2005, Urbina 2005).

Both the high prevalence of trypanosomiasis and the limitations to the treatments that are currently available indicate the need for new drugs that are ef-

+Corresponding author: cristina.herrera@ucr.ac.cr

Received 27 April 2009

Accepted 24 August 2009 fective, selective and well tolerated. The mechanism of action of natural and synthetic drugs against $T$. cruzi and their interactions with the mammalian host were reviewed by Maya et al. (2007).

Several imidazole and nitrofuran analogues have been tested against $T$. cruzi and these analogues have been found to exert similar activities against the epimastigote and the trypomastigote forms (Pozas et al. 2005). Although megazol, a 5-nitroimidazole derivative, has been used to treat Trypanosoma brucei infection (Darsaud et al. 2004) and at least one study highlights its therapeutic efficacy against $T$. cruzi infection (Maya et al. 2003), its utility has been called into question as a result of reports that it can cause chromosomal alterations and DNA damage (Enanga et al. 2003, Nesslany et al. 2004).

In contrast, González et al. (2007) synthesized a series of bis-2,5-(4-guanidinophenyl) thiophenes that had antichagasic properties, but lacked cytotoxic effects. The most active of these compounds had an $\mathrm{IC}_{50}$ of $1.7 \mu \mathrm{M}$. Another thiophen derivative, 2-(5-nitrothiophen-2-ylmethylene) malononitrile, which is less structurally complex than the previous compounds, exerted a degree of anti-amastigote activity that was similar to nifurtimox and benznidazole; however, this compound was also a lot more cytotoxic than the reference drugs (Muelas-Serrano et al. 2002). The cytotoxic and antitumor effects of phenyl-2-nitropropenes were demonstrated two decades ago (Cassels et al. 1982).

Based on the cytotoxic characteristics of the phenyl2-nitropropenes and the potential pharmacophoric effect of the thiophene group, we decided to investigate the efficacy of thienyl-2-nitropropene compounds as $T$. cruzi inhibitors. Furthermore, we tested the effect of removing the nitro group of the aromatic system and placing it on a lateral chain that was conjugated with the $\pi$ system of the propene group. 
In this paper, the activities of four synthetic compounds related to thienyl-2-nitropropenes were tested in vitro against the amastigotes, epimastigotes and blood tripomastigotes of three strains of T. cruzi. Cytotoxicity tests were performed on Vero cells.

\section{MATERIALS AND METHODS}

Compounds-1-(3-benzothienyl)-2-nitropropene(N1), 1-(3-thienyl)-2-nitropropene (N2), 1-(5-bromo-2-thienyl)2-nitropropene (N3) and 1-(4-bromo-2-thienyl)-2nitropropene (N4) (Fig. 1) were assayed as possible agents against $T$. cruzi. We have previously reported the synthesis and NMR characterization of all of the nitropropenes used (Vallejos et al. 2005).

Biological assays - For the biological assays, the test substances were dissolved in $0.1 \%$ or less dimethyl sulphoxide (DMSO), according to the literature (De Souza et al. 2002, Kamnaing et al. 2003).

Parasites - Three strains of T. cruzi were used: the Jennifer strain, which was isolated in 2003 from an acute case of Chagas disease in a Costa Rican child (6 years old), the GA strain, which was isolated in 1998 from an adult (48 years old) from Costa Rica and the CL transgenic strain (kindly donated by the Universidad Complutense, Madrid), as defined by Le-Senne et al. (2002). Epimastigotes were grown on LIT medium supplemented with $10 \%$ bovine foetal serum (bfs). Blood trypomastigotes were harvested in Locke solution and the intracellular forms were obtained from Vero cells, as described below.

Cell cultures - Vero cells were cultivated on Dulbecco's Minimal Essential Medium (Sigma-Aldrich) supplemented with $10 \%$ bfs, $20 \mu \mathrm{M}$ 4-(2-hydroxyethyl)1-piperazineethanesulfonic acid and antibiotics (bencilpenicillin $200 \mu \mathrm{g} / \mathrm{mL}$ - streptomycin $200 \mathrm{U} / \mathrm{mL}$ ).

Cytotoxicity test - 40,000 Vero cells/well were incubated overnight on 96 -well plates at $37^{\circ} \mathrm{C}$ with $\mathrm{CO}_{2}(5 \%)$. The cells were exposed to different concentrations of the

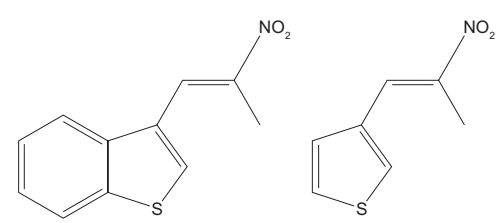

N1

N2

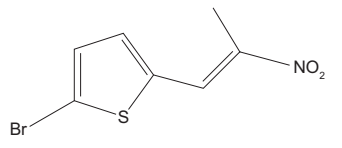

N3

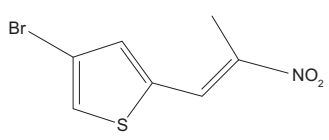

N4

Fig. 1: chemical structures of thienyl-2-nitropropene [N1: 1-(3-benzothienyl)-2-nitropropene; N2: 1-(3-thienyl)-2-nitropropene; N3: 1-(5-bromo-2-thienyl)-2-nitropropene; N4: 1-(4-bromo-2thienyl)-2-nitropropene]. compounds (100-3 $\mu \mathrm{M}$ ) for a period of $24 \mathrm{~h}$ (Sánchez et al. 2002). Cell quantification was performed using the 3-(4,5-dimetyltiazol-2-yl)-2,5-diphenyltetrazolide bromide (MTT) reduction method that was described by Mosman (1983), with the following slight modification: to increase sensitivity and reduce the speed of transformation of MTT to formazan, $5 \mathrm{mg} / \mathrm{mL}$ of MTT were supplemented with $2 \mathrm{mM}$ phenazine methosulphate (PMS). After incubation for $45 \mathrm{~min}$, the supernatants were extracted, the cells were washed twice with PBS ( $\mathrm{pH}$ 7.2) and formazan crystals were dissolved in 100 $\mu \mathrm{L}$ DMSO. The absorbance was quantified on a Termo Labsystems ${ }^{\circledR}$ microplate reader at $540 \mathrm{~nm}$.

Activity against epimastigotes expressed as $I C_{50}-\mathrm{A}$ total of $1 \times 10^{6}$ epimastigotes $/ \mathrm{mL}$ were incubated with different concentrations of the compounds $(100-0.1 \mu \mathrm{M})$ for periods of $72 \mathrm{~h}$ at $28^{\circ} \mathrm{C}$. The Jennifer strain and the CL strain epimastigotes were quantified by the reduction of MTT/PMS, as described previously (Mosman 1983).

Activity against amastigotes expressed as $I C_{50}$ - A total of 4,000 Vero cells/well were incubated overnight in 96-well plates. Cells were then infected for 2 $\mathrm{h}$ with either 20 parasites/cell of the Jennifer strain or 10 parasites/cell of the CL strain. Non-infective parasites were removed with PBS and the cells were incubated with different concentrations of the compounds for six days. The number of intracellular parasites was determined indirectly by counting the numbers of extracellular parasites in a Neubauer chamber (Hyde \& Dvorak 1973).

Activity against trypomastigotes - Trypomastigotes of the GA strain were isolated from the heart blood of Balb/c infected mice, diluted in Alsever's solution and centrifuged at $206 \mathrm{~g}$ to eliminate the red cells. The supernatant was collected and then centrifuged at 1,288 $\mathrm{g}$ and the pellet was resuspended to a concentration of $1 \times 10^{6}$ trypomastigotes $/ \mathrm{mL}$. A $25 \mu \mathrm{L}$ volume of the suspension (25,000 parasites/well) was exposed to different concentrations of the compounds $(100-6.25 \mu \mathrm{M})$ in $25 \mu \mathrm{L}$ of Locke solution, for a period of $4 \mathrm{~h}$. DMSO (0.5\%) was used as a positive control and Locke solution was used as a negative control. The numbers of parasites and their motility were determined using an inverted light microscope and 400X amplification. The experiments were performed twice for each concentration of the drugs; these assays are considered to be preliminary tests.

Statistical analysis - The cytotoxicity percentage (CP) against Vero cells and the activity percentages (AP) against epimastigotes and amastigotes were calculated using the following formula: AP (or CP) $=(1-\mathrm{Mt} /$ Mc)*100 (Muelas et al. 2002, Sánchez et al. 2002, Petray et al. 2004), where Mt represents the measurement taken after the treatment and $\mathrm{Mc}$ is the measurement of the negative control. Each concentration of the compounds was assayed in triplicate on the same day and the assays were repeated at least three times on different days. The $\mathrm{IC}_{50}$ value for each compound was calculated by plotting the AP (or CP) against the logarithm of the com- 
pound concentration for each assay (Petray et al. 2004). Comparisons of the mean $\mathrm{IC}_{50}$ values were made using the one-tailed ANOVA with the Tukey test as a post-hoc test. Differences with a p-value equal to or less than 0.05 were considered to be significant.

\section{RESULTS}

The $\mathrm{IC}_{50}$ values of compounds N1, N2, N3 and N4 for cytotoxicity against Vero cells, epimastigotes and amastigotes are shown in Table I and Fig. 2. Statistical analysis of the $\mathrm{IC}_{50}$ values revealed that $\mathrm{N} 2$ exerted significantly less cytotoxicity against Vero cells than the other three compounds N1 $(\mathrm{p}=0.014), \mathrm{N} 3(\mathrm{p}=0.001)$ and $\mathrm{N} 4(\mathrm{p}=0.002)$.

In contrast, N1 was the most active compound against epimastigotes of the Jennifer strain. The effect of N1 was significantly larger than that produced by either $\mathrm{N} 2(\mathrm{p}=0.001)$ or $\mathrm{N} 4(\mathrm{p}=0.037)$; however, there was no significant difference between the effects produced by $\mathrm{N} 1$ and those of $\mathrm{N} 3(\mathrm{p}=0.390)$. Compared to N2, there were significant differences in the $\mathrm{IC}_{50}$ values of $\mathrm{N} 3(\mathrm{p}$ $=0.002)$ and $\mathrm{N} 4(\mathrm{p}=0.017)$ against epimastigotes of the Jennifer strain. Similarly, N1 was also the most active compound against epimastigotes of the CL strain; the effects resulting from the use of N1 were significantly different from those produced by $\mathrm{N} 2(\mathrm{p}=0.001)$ and $\mathrm{N} 4$ $(p=0.008)$, but they were not different to $\mathrm{N} 3(\mathrm{p}=0.970)$. Compared to $\mathrm{N} 2$, the $\mathrm{IC}_{50}$ values of $\mathrm{N} 3(\mathrm{p}=0.001)$ and $\mathrm{N} 4(\mathrm{p}=0.007)$ against epimastigotes of the CL strain were significantly different. The activity of each compound against epimastigotes was similar for both the Jennifer and CL strains.

N1, N3 and N4 exhibited comparable activities against amastigotes of the Jennifer strain. The $\mathrm{IC}_{50}$ value of $\mathrm{N} 2$ was significantly different to the $\mathrm{IC}_{50}$ values of each of the other three compounds: $\mathrm{N} 1(\mathrm{p}=0.001)$, $\mathrm{N} 3(\mathrm{p}=0.001)$ and N4 $(\mathrm{p}=0.001)$. A similar result was obtained against amastigotes of the CL strain. N2 was found to have lower efficacy than each of the other three compounds: $\mathrm{N} 1(\mathrm{p}=0.001), \mathrm{N} 3(\mathrm{p}=0.001)$ and $\mathrm{N} 4(\mathrm{p}=$ 0.001 ). There were no significant differences in the activities of any of the four compounds between amastigotes of the Jennifer strain and those of the CL strain.

When tested against trypomastigotes of the GA strain, all compounds produced decreases in parasite motility and small reductions in the amount of parasites. N1 ex-

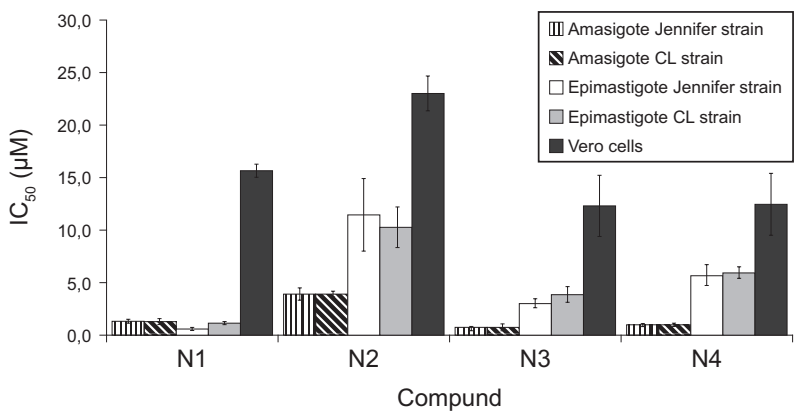

Fig. 2: $\mathrm{IC}_{50}$ values against Vero cells, epimastigotes and amastigotes of 1-(3-benzothienyl)-2-nitropropene (N1), 1-(3-thienyl)-2-nitropropene (N2), 1-(5-bromo-2-thienyl)-2-nitropropene (N3) and 1-(4-bromo-2thienyl)-2-nitropropene (N4) compounds.

erted the highest activity, followed by N3 and N4 (which had similar levels of activity). N2 exhibited the lowest activity (Table II). At a concentration of $12.5 \mu \mathrm{M}, \mathrm{N} 1$ and $\mathrm{N} 4$ decreased the numbers of parasites after $4 \mathrm{~h}$, whereas $\mathrm{N} 2$ and N3 did not. At a concentration of $6.25 \mu \mathrm{M}$, all of the compounds decreased the motility of parasites after $4 \mathrm{~h}$. A greater suppression of activity was observed when $12.5 \mu \mathrm{M}$ concentrations of $\mathrm{N} 1$ and $\mathrm{N} 4$ were used.

\section{DISCUSSION}

The four compounds under investigation in our study were found to exert differential toxic effects against Vero cells and all parasitic forms at different concentrations. These results suggest that, in contrast to mammalian cells, the four compounds exhibit a degree of specificity for parasites. The most pronounced differences were observed with compound N1, which was found to be the most active against all parasite forms tested.

As N1 had the greatest effect against both epimastigotes and trypomastigotes, followed by N3, N4 and finally $\mathrm{N} 2$, it might be suggested that these compounds act on a similar target in the flagellar forms of parasites and that their effects are independent of the parasite strain used.

In contrast, the activities of the compounds against amastigotes showed a different pattern. Whereas compounds N1, N3 and N4 exerted a similarly high inhibitory effect against amastigotes, N2 produced only modest activity.

\section{TABLE I}

$\mathrm{IC}_{50}(\mu \mathrm{M})$ values against Vero cells, epimastigotes and amastigotes of Jennifer and CL strain

\begin{tabular}{lcccrr}
\hline & & \multicolumn{2}{c}{ Epimastigotes } & \multicolumn{2}{c}{ Amastigotes } \\
\cline { 3 - 6 } Compound & Vero cells & Jennifer & CL & Jennifer & $1.3 \pm 0.2$ \\
\hline N1 & $15.6 \pm 0.6$ & $0.6 \pm 0.2$ & $1.1 \pm 0.3$ & $3.8 \pm 0.6$ & $3.3 \pm 0.2$ \\
N2 & $23.1 \pm 1.7$ & $11.5 \pm 3.4$ & $10.3 \pm 1.9$ & $3.9 \pm 0.3$ \\
N3 & $12.4 \pm 2.9$ & $3.0 \pm 0.5$ & $3.9 \pm 0.7$ & $0.6 \pm 0.6$ & $0.7 \pm 0.2$ \\
N4 & $12.5 \pm 2.8$ & $5.6 \pm 1.2$ & $6.0 \pm 0.6$ & $1.1 \pm 0.1$ & $1.0 \pm 0.1$ \\
\hline
\end{tabular}


TABLE II

Activity of each compound against trypomastigotes of GA strain

\begin{tabular}{|c|c|c|c|c|c|c|c|c|c|c|c|}
\hline \multirow[b]{2}{*}{ Compound } & \multirow{2}{*}{$\begin{array}{l}\text { Concentration } \\
(\mu \mathrm{M})\end{array}$} & \multicolumn{5}{|c|}{ Amount of parasites ${ }^{a}$ and time (min) } & \multicolumn{5}{|c|}{ Motility of parasites ${ }^{b}$ and time (min) } \\
\hline & & 30 & 60 & 120 & 180 & 240 & 30 & 60 & 120 & 180 & 240 \\
\hline \multirow[t]{5}{*}{ N1 } & 100 & ++++ & +++ & ++ & + & + & ++ & + & + & + & + \\
\hline & 50 & ++++ & ++++ & +++ & ++ & + & +++ & ++ & + & + & + \\
\hline & 25 & ++++ & ++++ & +++ & ++ & ++ & +++ & ++ & ++ & ++ & + \\
\hline & 12.5 & ++++ & ++++ & ++++ & ++++ & +++ & ++++ & +++ & +++ & ++ & ++ \\
\hline & 6.25 & ++++ & ++++ & ++++ & ++++ & ++++ & ++++ & +++ & +++ & +++ & +++ \\
\hline \multirow[t]{5}{*}{ N2 } & 100 & ++++ & ++++ & ++++ & ++++ & +++ & +++ & +++ & ++ & ++ & + \\
\hline & 50 & ++++ & ++++ & ++++ & ++++ & +++ & +++ & +++ & +++ & ++ & ++ \\
\hline & 25 & ++++ & ++++ & ++++ & ++++ & ++++ & +++ & +++ & +++ & ++ & ++ \\
\hline & 12.5 & ++++ & ++++ & ++++ & ++++ & ++++ & ++++ & +++ & +++ & +++ & +++ \\
\hline & 6.25 & ++++ & ++++ & ++++ & ++++ & ++++ & ++++ & +++ & +++ & +++ & +++ \\
\hline \multirow[t]{5}{*}{ N3 } & 100 & ++++ & ++++ & +++ & ++ & + & ++ & + & + & + & + \\
\hline & 50 & ++++ & ++++ & ++++ & +++ & ++ & +++ & ++ & ++ & ++ & + \\
\hline & 25 & ++++ & ++++ & ++++ & ++++ & +++ & ++++ & +++ & +++ & +++ & + \\
\hline & 12.5 & ++++ & ++++ & ++++ & ++++ & ++++ & ++++ & +++ & +++ & +++ & +++ \\
\hline & 6.25 & ++++ & ++++ & ++++ & ++++ & ++++ & ++++ & +++ & +++ & +++ & +++ \\
\hline \multirow[t]{5}{*}{ N4 } & 100 & ++++ & +++ & +++ & + & + & ++ & + & + & + & + \\
\hline & 50 & ++++ & ++++ & ++++ & +++ & ++ & +++ & ++ & ++ & + & + \\
\hline & 25 & ++++ & ++++ & ++++ & ++++ & +++ & +++ & +++ & +++ & ++ & ++ \\
\hline & 12.5 & ++++ & ++++ & ++++ & ++++ & +++ & ++++ & +++ & +++ & +++ & ++ \\
\hline & 6.25 & ++++ & ++++ & ++++ & ++++ & ++++ & ++++ & ++++ & +++ & +++ & +++ \\
\hline Locke solution & & ++++ & ++++ & ++++ & ++++ & ++++ & ++++ & ++++ & ++++ & ++++ & ++++ \\
\hline DMSO $0.5 \%$ & & ++++ & ++++ & +++ & +++ & ++ & +++ & +++ & +++ & +++ & ++ \\
\hline
\end{tabular}

$a$ : amount of parasites (++++: parasites with normal motility; +++ : parasites with slow and normal motility; ++ : parasites with slow motility; +: parasites with slow motility and without motility); $b$ : motility (++++: more than 20 parasites; +++: 11-20 parasites; ++: 6-10 parasites; +: 1-5 parasites); DMSO: dimethyl sulphoxide; N1: 1-(3-benzothienyl)-2-nitropropene; N2: 1-(3-thienyl)2-nitropropene; N3: 1-(5-bromo-2-thienyl)-2-nitropropene; N4: 1-(4-bromo-2-thienyl)-2-nitropropene.

Compared to the epimastigote forms, an activityswitch was observed for compounds N2, N3 and N4 against amastigotes; however, this behaviour was not observed for N1. Although no definitive conclusions can be drawn, it might be hypothesized that metabolic differences between the distinct forms of the parasite could account for the varying effects of N1. However, although the incubation periods for the blood forms lasted for less than $72 \mathrm{~h}$, the experiments against the amastigotes were conducted over a period of six days; therefore, compared to the other compounds, faster inactivation of $\mathrm{N} 1$ in the latter case might partially explain these results.

The four compounds, N1, N2, N3 and N4, share the same thienyl-2-nitropropene structure; therefore, the differences in their activity are related to the presence of benzene in N1, but bromide in N3 and N4. If N1, N2, $\mathrm{N} 3$ and N4 interacted with a protein, they might fit into a hydrophobic pocket. Under this assumption, because it is the most bulky side substituent, the benzene in N1 would fit better into the hydrophobic pocket; this would be followed by the bromide groups in N3 and N4. In the case of N2, the absence of a hydrophobic substituent, leads to a decrease in its activity. As one may expect a general increase in activity against $T$. cruzi with the presence of hydrophobic and bulky substitutions at positions 2 and 3 of the thiophen group, this could be very important. Therefore, to increase its activity, it is possible that compound $\mathrm{N} 1 \mathrm{might}$ be chemically modified.

To compare the effect of the nitropropene group with that of the aminopropane group, we proposed the synthesis of the following thienyl-2-aminopropanes compounds: 1-(3-benzothienyl)-2-aminopropane (A1), 1-(3-Thienyl)-2-aminopropane (A2) and 1-(5-bromo-2thienyl)-2-aminopropane (A3) from thienyl-2-nitropropene compounds $\mathrm{N} 1, \mathrm{~N} 2$ and $\mathrm{N} 3$ (in which the nitro groups were reduced to amino groups), respectively. The compounds A1, A2 and A3 did not show activity against both epimastigotes and trypomastigotes. These data suggest that the nitropropene group is important for the activity of the compounds (unpublished observations).

In summary, two properties of the compounds that we investigated appear to be responsible for their activity against the T. cruzi parasite: (i) the thiophene group, which is present in each of the four compounds, resembles the imidazole and tiazole groups that bind iron from the haem groups of the cytochrome P450 enzymes 
and thereby inhibit its function (De Souza et al. 2002) and (ii) the nitro group, which might produce oxidative stress by interacting with macromolecules through the production of nitrous derivatives (Henderson et al. 1988, Stoppani 1999, Cerecetto et al. 2000, Muelas et al. 2002, Enanga et al. 2003, De Oliveira et al. 2003, 2006, Maya et al. 2003, Olea-Azar et al. 2003, Stewart et al. 2004, Pozas et al. 2005, Quesada et al. 2006).

\section{REFERENCES}

Cassels BK, Herreros S, Ibanez C, Rezende MC, Sebastian C, Sepúlveda S 1982. Synthesis of antitumoral 1-aryl-2-nitroalkenes. An Asoc Quim Argent 70: 283-288.

Cerecetto H, Di Maio R, González M, Risso M, Sagrera G, Seoane G, Denicola A, Peluffo G, Quijano C, Stoppani AOM, Paulino M, Olea-Azar C, Basombrio MA 2000. Synthesis and antitrypanosomal evaluation of $E$-isomers of 5-nitro-2-furaldehyde and 5-nitrothiophene-2-carboxaldehyde semicarbazone derivatives, structure-activity relationships. Eur J Med Chem 35: 343-350.

Cerecetto H, González M 2008. Anti-T. cruzi agents: our experience in the evaluation of more than five hundred compounds. Mini Rev Med Chem 8: 1355-1383.

Coura JR, De Castro SL 2002. A critical review on Chagas disease chemotherapy. Mem Inst Oswaldo Cruz 97: 3-24.

Darsaud A, Chevrier C, Bourdon L, Dumas M, Buguet A, Bouteille B 2004. Megazol combined with suramin improves a new diagnosis index of the early meningo-encephalitic phase of experimental African trypanosomiasis. Trop Med Int Health 9: 83-91.

De Oliveira RB, Passos APF, Alves RO, Romanha AJ, Prado MAF, Souza FJ, Alves RJ 2003. In vitro evaluation of the activity of aromatic nitrocompounds against Trypanosoma cruzi. Mem Inst Oswaldo Cruz 98: 141-144.

De Oliveira RB, Vaz ABM, Alves RO, Liarte DB, Donnici CL, Romanha AJ, Zani CL 2006. Arylfurans as potential Trypanosoma cruzi trypanothione reductase inhibitors. Mem Inst Oswaldo Cruz 101: 169-173.

De Souza AO, Hemerly FP, Melo PS, Machado GMC, Miranda CC, Santa-Rita RM, Haun M, León LL, Sato DN, De Castro SL, Durán N 2002. 3-[4'-Bromo-(1,1'-biphenyl)-4-yl]- $N, N$-dimethyl3-(2-thienyl)-2-propen-1-amine: synthesis, cytotoxicity and leishmanicidal, trypanocidal and antimycobacterial activities. J Antimicrob Chemother 50: 629-637.

Dias JPC, Silveira AC, Schofield CJ 2002. The impact of Chagas disease control in Latin America - A review. Mem Inst Oswaldo Cruz 97: 603-612.

Docampo R 2001. Recent developments in the chemotherapy of Chagas disease. Curr Pharm Des 7: 1157-1164.

Enanga B, Ariyanayagam MR, Stewart ML, Barrett MP 2003. Activity of megazol, a trypanocidal nitroimidazole, is associated with DNA damage. Antimicrob Agents Chemother 47: 3368-3370.

González JL, Stephens CE, Wenzler T, Brun R, Tanious FA, Wilson WD, Barszcz T, Werbovetz KA, Boykin DW 2007. Synthesis and antiparasitic evaluation of bis-2,5-[4-guanidinophenyl]thiophenes. Eur J Med Chem 42: 552-557.

Henderson GB, Ulrich P, Fairlambt AH, Rosenberg I, Pereira M, Sela M, Cerami A 1988. "Subversive" substrates for the enzyme trypanothione disulfide reductase: alternative approach to chemotherapy of Chagas disease. Biochemistry 85: 5374-5378.

Hyde TP, Dvorak JA 1973. Trypanosoma cruzi: interaction with vertebrate cells in vitro. Quantitative analysis of the penetration phase. Exp Parasitol 34: 284-294.
Kamnaing P, Tsopmo A, Tanifum EA, Tchuendem MHK, Tane P, Ayafor JF, Sterner O, Rattendi D, Iwu MM, Schuster B, Bacchi C 2003. Trypanocidal diarylheptanoids from Aframomun letestulnum. J Nat Prod 66: 364-367.

Kirchhoff LV 2005. Trypanosomiasis. In: DL Kasper, AS Fauci, DL Longo, E Braunwald, SL Hauser, JL Jameson. Harrison's principles of internal medicine, 16th edition, Mac Graw Hill, New York, p. 1373-1377.

Le-Senne A, Muelas S, Fernando C, Escario JA, Gómez A 2002. Biological characterization of a $\beta$-galactosidase expressing clone of Trypanosoma cruzi CL strain. Mem Inst Oswaldo Cruz 97: 1101-1105.

Mady C, Ianni BM, de Souza JL 2008. Benznidazole and Chagas disease: can an old drug be the answer to an old problem? Expert Opin Investig Drugs 17: 1427-1433.

Maya JD, Bollo S, Nuñez-Vergara LJ, Squella JA, Repetto Y, Morillo A, Perie J, Chauviere G 2003. Trypanosoma cruzi: effect and mode of action of nitroimidazole and nitrofuran derivatives. Biochem Pharmacol 65: 999-1006.

Maya JD, Cassels BK, Iturriaga-Vásquez P, Ferreira J, Faúndez M, Galanti N, Ferreira A, Morello A 2007. Mode of action of natural and synthetic drugs against Trypanosoma cruzi and their interaction with the mammalian host. Comp Biochem Physiol 146: 601-620.

Mecca MM de, Bartel LC, Castro CR de, Castro JA 2008. Benznidazole biotransformation in rat heart microsomal fraction without observable ultrastructural alterations: comparison to nifurtimoxinduced cardiac effects. Mem Inst Oswaldo Cruz 103: 549-553.

Moncayo A 2003. Chagas disease: current epidemiological trends after the interruption of vectorial and transfusional transmission in the Southern Cone countries. Mem Inst Oswaldo Cruz 98: 577-591.

Mosmann T 1983. Rapid colorimetric assay for cellular growth and survival: application to proliferation and cytotoxicity assays. J Immunol Methods 65: 55-63.

Muelas-Serrano S, Le-Senne A, Fernández-Portillo C, Nogal JJ, Ochoa C, Gómez-Barrio A 2002. In vitro and in vivo anti-Trypanosoma cruzi activity of a novel nitro-derivative. Mem Inst Oswaldo Cruz 97: 553-557.

Nesslany F, Brugier S, Mouries MA, Le Curieux F, Marzin D 2004. In vitro and in vivo chromosomal aberrations induced by megazol. Mutat Res Genet Toxicol Environ Mutagen 560: 147-158.

Olea-Azar C, Rigol C, Mendizabal F, Morello A, Maya JD, Repetto Y, Aguirre G, Cerecetto H, Di Maio R, González M, Porcal W 2003. ESR spin trapping studies of free radicals generated from nitrofuran derivative analogues of nifurtimox by electrochemical and Trypanosoma cruzi reduction. Free Radic Res 37: 993-1001.

Petray PB, Morilla MJ, Corral RS, Romero EL 2004. In vitro activity of etanidazole against the protozoan parasite Trypanosoma cruzi. Mem Inst Oswaldo Cruz 99: 233-235.

Pozas R, Carballo J, Castrob C, Rubiob J 2005. Synthesis and in vitro antitrypanosomal activity of novel nifurtimox analogues. Bioorg Med Chem Lett 15: 1417-1421.

Quesada A, Arguello J, Squella JA, JL Wardell, Lowd JN, Glidewell C 2006. Hydrogen-bonded supramolecular structures of three related 4-(5-nitro-2-furyl)-1,4-dihydropyridines. Acta Crystallogr C62: 8-12.

Rodríguez AJ 2005. Nuevas perspectivas en el manejo terapéutico de la enfermedad de Chagas. Rev Peru Med Exp Salud Publica 22: 123-133. 
Sánchez G, Cuellar D, Zulantay I, Gajardo M, González-Martin G 2002. Cytotoxicity and trypanocidal activity of nifurtimox encapsulated in ethylcyanoacrylate nanoparticles. Biol Res 35: 39-45.

Stewart M, Jiménez G, Baliani A, Klenke B, Brun R, Brock JM, Gilbert IH, Barrett MP 2004. Trypanocidal activity of melamine-based nitroheterocycles. Antimicrob Agents Chemother 48: 1733-1738.

Stoppani AOM 1999. Quimioterapia de la Enfermedad de Chagas. Medicina 59: 147-165.

Urbina JA 1999. Parasitological cure of Chagas disease: is it possible? Is it relevant? Mem Inst Oswaldo Cruz 94 (Suppl. I): 349-355.
Urbina JA 2002. Chemotherapy of Chagas disease. Curr Pharm Des 8: 287-295.

Urbina JA 2005. Nuevos avances en el desarrollo del tratamiento etiológico de la enfermedad de Chagas. Mesas de Debate, OMS/ OPS, Buenos Aires, 9 pp.

Urbina JA, Docampo R 2003. Specific chemotherapy of Chagas disease: controversies and advances. Trends Parasitol 19: 495-501.

Vallejos G, Fierro A, Rezende MC, Sepúlveda-Boza S, Reyes-Parada M 2005. Heteroarylisopropylamines as MAO inhibitors. Bioorg Med Chem 13: 4450-4457. 